Rev. Bras. Saúde Prod. Anim., Salvador, v.16, n.3, p.591-605 jul./set.., 2015 http://www.rbspa.ufba.br

\title{
Composição do leite de vacas alimentadas com diferentes fontes de compostos nitrogenados
}

\section{Milk composition of cows fed with different sources of nitrogen compounds}

\author{
AGUIAR, Ana Cássia Rodrigues de ${ }^{1}$; ROCHA JÚNIOR, Vicente Ribeiro ${ }^{1 *}$; \\ CALDEIRA, Luciana Albuquerque ${ }^{1}$; ALMEIDA FILHO, Silvio Humberto Cardoso \\ $\mathrm{de}^{1}$; RUAS, José Reinaldo Mendes ${ }^{2}$; SOUZA, Vanice Mendes de ${ }^{1}$; COSTA, Maria \\ Dulcinéia da ${ }^{1}$; PIRES, Daniel Ananias de Assis ${ }^{1}$
}

\footnotetext{
${ }^{1}$ Universidade Estadual de Montes Claros, Departamento de Ciências Agrárias, Janaúba, Minas Gerais, Brasil.

${ }^{2}$ Empresa de Pesquisa Agropecuária de Minas Gerais, Fazenda Experimental do Gorutuba, Nova Porteirinha, Minas Gerais, Brasil.

*Endereço para correspondência: vicente.rocha@unimontes.br
}

\section{RESUMO}

Objetivou-se avaliar a composição físico-química e o perfil de ácidos graxos do leite de vacas alimentadas com diferentes fontes de compostos nitrogenados (farelo de soja, ureia, farelo de girassol e farelo de mamona detoxicado). $\mathrm{O}$ delineamento experimental foram dois quadrados latinos 4 × 4, sendo utilizadas oito vacas F1 Holandês/Zebu, com produção média de $20 \mathrm{Kg}$ de leite com 3,5\% de gordura dia ${ }^{-1}$. Amostras de leite foram coletadas e analisadas quanto à composição físico-química e perfil de ácidos graxos. Com exceção do nitrogênio ureico no leite, que foi maior na dieta com ureia, as demais variáveis da composição físico-química não foram influenciadas pelas dietas com diferentes fontes de compostos nitrogenados. Quanto ao perfil de ácido graxo houve variação nas concentrações dos ácidos C4:0; C18:0; C10:1; C12:1 e C18:1 T10 T11 T12. No entanto, para os totais de ácidos graxos saturados, monoinsaturados e poliinsaturados no leite, estes não diferiram entre as fontes de compostos nitrogenados. O uso de diferentes fontes de compostos nitrogenados na dieta de vacas F1 Holandês x Zebu, com produção média de $20 \mathrm{Kg}$ de leite com $3,5 \%$ de gordura dia $^{-1}$, não altera a composição físico-química do leite, com exceção do nitrogênio uréico que aumenta na dieta com ureia. Entretanto, pode modificar o perfil de ácidos graxos da gordura do leite.

Palavras-chave: ácidos graxos, físico-química, nitrogênio não protéico, nutrição, proteína, vacas mestiças

\section{SUMMARY}

Objective was to evaluate the physic-chemical composition and the fatty acid profile of milk from cows fed with different sources of nitrogen compounds (soybean meal, urea, sunflower meal and detoxified castor bean meal). The experimental design was two 4 x 4 Latin squares, being used eight F1 Holstein / Zebu cows, with an average production of $20 \mathrm{~kg}$ of milk with $3.5 \%$ fat day-1. Milk samples were collected and analyzed for physico-chemical composition and fatty acid profile. With the exception of milk urea nitrogen, which was higher in the diet with urea, the other variables of the physic-chemical composition were not affected by diets with different sources of nitrogen compounds. Regarding the fatty acid profile was no change in the concentrations of acid C4: 0, C18: 0, C10: 1, C12: 1 and C18: 1 T10 T11 T12. However, for total saturated, monounsaturated and polyunsaturated fatty acids in milk, there were no differences among the sources of nitrogen compounds. The use of different sources of nitrogen compounds in the diet of F1 Holstein $x$ Zebu cows, with an average production of $20 \mathrm{~kg}$ of milk with $3.5 \%$ fat day-1 does not alter the physic-chemical composition of milk, with the exception of milk urea nitrogen which increases with dietary urea. However, it you can modify the profile of milk fatty acids.

Keywords: fatty acids, physic-chemical, nonprotein nitrogen, nutrition, protein, crossbred cows 
Rev. Bras. Saúde Prod. Anim., Salvador, v.16, n.3, p.591-605 jul./set.., 2015 http://www.rbspa.ufba.br

\section{INTRODUÇÃO}

O custo de alimentos tradicionais tem se tornado limitante para sistemas de produção animal. A inclusão de fontes protéicas alternativas na alimentação de vacas em lactação tem como principal objetivo baixar os custos com a alimentação e manter os níveis de produção e a qualidade do leite (KROLOW et al., 2012; PINA et al., 2006).

Muitos estudos têm correlacionado a suplementação de proteína na dieta com seu metabolismo (BRODERICK \& REYNAL, 2009; CHIZZOTTI et al., 2007; HOJMAN et al., 2004), por meio das concentrações no plasma, sangue e leite, com o objetivo de maximizar o uso de nitrogênio na ração de vacas leiteiras, explorando a utilização de fontes protéicas e seus benefícios sobre a produção, qualidade e processamento do leite. De acordo com Aquino et al. (2009), a utilização de nitrogênio não protéico (NNP) pode alterar a composição da proteína do leite, influenciando o processamento industrial da matéria prima, já que os teores de proteína verdadeira e da caseína têm influência direta sobre a fabricação de queijo.

O manejo da nutrição constitui a principal estratégia para alterar a composição do leite (NUDDA et al., 2014; OLIVEIRA et al., 2007) a fim de atender distintas demandas de mercado. Uma das características do leite bovino é a grande proporção de ácidos graxos saturados (AG), com cadeias de 4 a 16 carbonos, resultantes da síntese de novo. Alguns destes AG são apontados como precursores do colesterol presente nas lipoproteínas de baixa densidade (LDL), responsável por doenças cardiovasculares. Segundo Benchaar et al. (2007), o perfil de ácidos graxos no leite pode ser alterado por modificações no padrão de fermentação ruminal e espécies de bactérias ruminais. Desta forma, a utilização de diferentes fontes de compostos nitrogenados na dieta de vacas em lactação poderia alterar o equilíbrio da microbiota ruminal $\mathrm{e}$ consequentemente $\mathrm{o}$ perfil de fermentação e do conteúdo que chega ao duodeno. De acordo com Vlaeminck et al. (2006), parte dos ácidos graxos que compõem a gordura do leite vêm da absorção intestinal de lipídeos de membrana provenientes das bactérias do rumem.

Portanto, considerando-se também que a maior parte da produção de leite no Brasil é oriunda de vacas mestiças de holandês, objetivou-se avaliar a composição físico-química e perfil de ácidos graxos do leite de vacas F1 Holandês/Zebu (H/Z) alimentadas com dietas com diferentes fontes de compostos nitrogenados.

\section{MATERIAL E MÉTODOS}

O experimento foi conduzido na Fazenda Experimental da Universidade Estadual de Montes Claros UNIMONTES, localizada no Município de Janaúba/MG. Foram utilizadas oito vacas $\mathrm{F} 1 \mathrm{H} / \mathrm{Z}$, da terceira ordem de lactação, com produção média de $20 \mathrm{~kg}$ de leite corrigido para $3,5 \%$ de gordura $\operatorname{dia}^{-1}$, e com período médio de lactação, ao início do experimento, de 80 dias. $\mathrm{O}$ delineamento experimental adotado foram dois quadrados latinos $4 \times 4$, compostos de quatro animais, quatro tratamentos e quatro períodos experimentais cada. Foram utilizadas 4 dietas experimentais, uma para cada uma das fontes nitrogenadas (farelo de soja, ureia, farelo de girassol, farelo de mamona detoxificado). $\mathrm{O}$ experimento 
Rev. Bras. Saúde Prod. Anim., Salvador, v.16, n.3, p.591-605 jul./set.., 2015 http://www.rbspa.ufba.br ISSN 15199940

teve duração de 72 dias, sendo dividido em quatro períodos de 18 dias, sendo que os 14 primeiros dias de cada período foram reservados para adaptação dos animais às dietas e os quatro últimos para coleta de dados e amostras.

Os animais foram mantidos em galpão coberto com estrutura metálica onde continham as baias individuais de $20 \mathrm{~m}^{2}$, com piso de cimento, separadas por estruturas de ferro, dotadas de cochos e bebedouros. As dietas foram formuladas conforme o NRC (2001) para vacas com média de $500 \mathrm{~kg}$ de peso corporal e produção média de $20 \mathrm{~kg}$ de leite corrigido para $3,5 \%$ de gordura $\mathrm{dia}^{-1}$. As dietas foram formuladas para serem isoprotéicas e isoenergéticas e foram fornecidas às vacas duas vezes por dia, às $08: 00 \mathrm{~h}$ e às 16:00h. $\mathrm{O}$ volumoso utilizado foi silagem de sorgo que era pesado diariamente em balança digital, colocado nos respectivos cochos $\mathrm{e}$ misturado com os concentrados de cada tratamento. As sobras dos cochos eram pesadas e registradas diariamente. As dietas foram ajustadas de acordo com as sobras, mantendo uma relação volumoso:concentrado com base na MS de 70:30, de forma que as sobras representassem $10 \%$ da quantidade fornecida.

A composição química dos ingredientes utilizados nas dietas experimentais foi determinada conforme orientações descritas em Detmann et al. (2012) e o NDT das dietas experimentais foi estimado segundo NRC (2001). A proporção dos ingredientes e a composição química das dietas encontram-se na Tabela 1.

Tabela 1. Proporção dos ingredientes das dietas experimentais (\%) e composição química das dietas, na base da matéria seca (\%)

\begin{tabular}{|c|c|c|c|c|}
\hline \multirow[b]{2}{*}{ Ingredientes } & \multicolumn{4}{|c|}{ Dietas experimentais (\% MS) } \\
\hline & $\begin{array}{l}\text { Farelo de } \\
\text { soja }\end{array}$ & Ureia & $\begin{array}{l}\text { Farelo de } \\
\text { girassol }\end{array}$ & $\begin{array}{l}\text { Farelo de mamona } \\
\text { detoxificado }\end{array}$ \\
\hline Silagem de sorgo & 70,00 & 70,00 & 70,00 & 70,00 \\
\hline Farelo de soja & 11,94 & 0,00 & 0,00 & 0,00 \\
\hline Farelo de Girassol & 0,00 & 0,00 & 13,28 & 0,00 \\
\hline Farelo de Mamona detoxificado & 0,00 & 0,00 & 0,00 & 12,24 \\
\hline Milho moído & 17,14 & 27,18 & 15,80 & 16,84 \\
\hline Ureia: sulfato de amônio $(9: 1)$ & 0,00 & 1,90 & 0,00 & 0,00 \\
\hline Suplemento mineral & 0,92 & 0,92 & 0,92 & 0,92 \\
\hline \multicolumn{5}{|c|}{ Composição química } \\
\hline Matéria Seca (\%) & 30,43 & 30,78 & 31,79 & 30,92 \\
\hline Matéria Orgânica (\%) & 93,18 & 93,06 & 93,01 & 93,27 \\
\hline Proteína Bruta $(\%)$ & 12,05 & 13,06 & 13,29 & 12,30 \\
\hline NIDN (\%) & 0,44 & 0,41 & 0,42 & 0,43 \\
\hline NIDA (\%) & 0,02 & 0,02 & 0,02 & 0,02 \\
\hline Exttrato Etéreo (\%) & 1,15 & 1,27 & 2,33 & 1,73 \\
\hline Carboidratos Totais (\%) & 75,04 & 76,45 & 72,61 & 76,34 \\
\hline Carboidratos não fibrosos (\%) & 30,5 & 32,81 & 27,26 & 31,78 \\
\hline Fibra em detergente neutro $(\%)$ & 44,54 & 43,64 & 45,35 & 44,56 \\
\hline FDNcp (\%) & 44,15 & 40,23 & 45,32 & 42,31 \\
\hline Fibra em detergente ácido (\%) & 20,6 & 23,06 & 21,45 & 26,43 \\
\hline Lignina & 3,02 & 3,24 & 3,65 & 3,14 \\
\hline *Nutrientes Digestíveis Totais & 65,28 & 65,16 & 65,43 & 65,02 \\
\hline
\end{tabular}

NNIDN = nitrogênio insolúvel em detergente neutro; NIDA = nitrogênio insolúvel em detergente ácido; FFDNcP $=$ Fibra em detergente neutro corrigida para cinza e proteína; ${ }^{*}$ NRC (2001). 
A destoxificação do farelo de mamona foi feita segundo Anandan et al. (2005) utilizando-se hidróxido de cálcio. $\mathrm{O}$ farelo de mamona foi misturado com solução de hidróxido de cálcio em uma proporção de $3 \mathrm{~g} / \mathrm{ml}$ e a concentração de hidróxido de cálcio foi de $40 \mathrm{~g} / \mathrm{kg}$. O material tratado foi deixado durante a noite e exposta ao sol para secagem e posterior armazenamento em sacos.

Os animais foram ordenhados por ordenha mecânica, com bezerro ao pé, duas vezes ao dia, às 06:00 horas e às 14:00 horas. As amostras de leite de cada animal foram coletadas duas vezes ao dia, nos últimos quatro dias de cada período, sendo feito um pool das amostras do leite da ordenha da manhã e da tarde, proporcionalmente à quantidade produzida de manhã e à tarde. Após a ordenha de cada vaca, o leite foi homogeneizado e coletado uma amostra de $500 \mathrm{~mL}$. Posteriormente essas amostras foram encaminhadas ao Laboratório de Tecnologia de Produtos de Origem Animal da Unimontes - Campus de Janaúba e no mesmo dia foram realizadas as análises físico-químicas. A produção de leite de cada vaca foi registrada nos últimos quatro dias do período experimental, sendo corrigida para 3,5\% de gordura conforme equação proposta por Sklan et al. (1994).

Para determinação das características físico-químicas do leite, foram realizadas as seguintes análises, em triplicata: acidez titulável $\left({ }^{\circ} \mathrm{D}\right)$ realizada com uso da solução indicadora de fenolftaleína $(0,1 \%) ; \mathrm{pH}$, utilizando peagâmetro digital Tecnopon, densidade a $15^{\circ} \mathrm{C}$, pelo termolactodensímetro de Quevenne; teor percentual de gordura, pelo método de Gerber; proteína pelo método kjeldahl com multiplicação do percentual de nitrogênio pelo fator 6,38 ; cinzas pela incineração na mufla a $550^{\circ}$; e índice crioscópico $\left({ }^{\circ} \mathrm{H}\right)$, utilizando crioscópio eletrônico LAKTRON 312L. A porcentagem de lactose foi calculada pela diferença entre os constituintes sólidos (proteína, gordura e cinzas). O cálculo extrato seco total (EST) foi obtido a partir do Disco de Ackermann, e o extrato seco desengordurado (ESD) pela subtração do teor de gordura (BRASIL, 2006).

Ao final de cada período experimental, ou seja, a cada 18 dias foram coletadas amostras de leite para as analises de ureia, caseína e contagem de células somáticas (CCS). Essas amostras foram acondicionadas em frascos com conservante Bronopol e enviadas para a Clínica do Leite - ESALQ/USP Campus Piracicaba, onde foram realizadas as análises mencionadas anteriormente. $\mathrm{O}$ teor de nitrogênio uréico e o percentual de caseína do leite foram determinados pelo método Infravermelho - PO ANA 009 e a Contagem de Células Somáticas (CCS) foi determinada pelo método Citometria de Fluxo - PO ANA 008. A contagem de células somáticas (CCS) foi avaliada no presente estudo para monitorar a ocorrência de mastite subclínica das vacas estudadas, o que poderia influenciar a produção e composição do leite.

Após extração e metilação, as amostras transmetiladas dos ácidos graxos foram analisadas em cromatógrafo a gás modelo Focus CG-Finnigan, com detector de ionização de chama, coluna capilar CP-Sil 88 (Varian), com 100m de comprimento por $0,25 \mu \mathrm{m}$ de diâmetro interno e $0,20 \mu \mathrm{m}$ de espessura do filme. Os ácidos graxos foram identificados por comparação dos tempos de retenção dos ésteres metílicos das amostras com padrões de ácidos graxos de manteiga. Os ácidos graxos foram quantificados por normalização das áreas dos ésteres metílicos. Os resultados dos ácidos graxos foram expressos em $\mathrm{mg} / \mathrm{g}$ de gordura. A determinação do perfil de ácidos graxos foi realizada no 
Rev. Bras. Saúde Prod. Anim., Salvador, v.16, n.3, p.591-605 jul./set.., 2015 http://www.rbspa.ufba.br

Laboratório de Nutrição Animal da ESALQ-USP - Campus Piracicaba.

A qualidade nutricional da fração lipídica foi avaliada pelos dados de composição em ácidos graxos, empregando-se os seguintes cálculos: Índice de Aterogenecidade a) (IA) $=\{($ $\mathrm{C} 12: 0+(4 \times \mathrm{C} 14: 0)+\mathrm{C} 16: 0)\} /\left(\sum \mathrm{AGMI}\right.$ $\left.+\sum \omega 6+\sum \omega 3\right)$ e Índice de Trombogenicidade $(\mathrm{IT})=(\mathrm{C} 14: 0+\mathrm{C} 16: 0$ $+\mathrm{C} 18: 0) /\left\{\left(0,5 \times \sum\right.\right.$ AGMI $)+\left(0,5 \times \sum \omega 6\right.$ $\left.+\left(3 \times \sum \omega 3\right)+\left(\sum \omega 3 / \sum \omega 6\right)\right\}$, segundo Ulbricth e Southage (1991); b) razão entre ácidos graxos hipercolesterolêmicos e hipocolesterolêmicos $=(\mathrm{C} 14: 0+\mathrm{C} 16: 0) /$ (monoinsaturado + poliinsaturado) $\mathrm{e}$ Ácidos Graxos Desejáveis (AGD) = (insaturados $+\mathrm{C} 18: 0$ ) segundo Costa et al. (2008); c) Razão entre ácidos graxos poli-insaturados e ácidos graxos saturados e razão entre $\omega 6$ e $\omega 3$ (COSTA et al., 2008).

Os dados obtidos foram submetidos à análise de variância pelo programa SISVAR (FERREIRA, 2011). Quando significativas na análise de variância, as médias dos tratamentos foram comparadas pelo teste de Tukey ao nível de $5 \%$ de probabilidade.

\section{RESULTADOS E DISCUSSÃO}

Não foi observada diferença para a produção e teor de gordura no leite (Tabela 2) entre as dietas com diferentes fontes de compostos nitrogenados $(\mathrm{P}>0,05)$. É importante ressaltar que as vacas produziram leite com elevado teor de gordura superando o limite mínimo de $3 \%$ estabelecido pela Instrução Normativa 62 para o leite (BRASIL, 2011). Souza et al. (2015) trabalhando com vacas primíparas $\mathrm{F} 1 \mathrm{H} / \mathrm{Z}$, com 150 dias de lactação ao início do experimento, verificaram teor médio de gordura no leite de 3,52\%, valor este mais baixo aos encontrados no presente trabalho, o que pode está relacionado a diferenças na ordem e fase de lactação das vacas. Todavia, Freitas Júnior et al. (2008) ao avaliarem o efeito do escore de condição corporal ao parto sobre o desempenho produtivo de vacas multíparas, mestiças $\mathrm{H} / \mathrm{Z}$, constataram teor médio de gordura no leite de 4\%. Já Saran Netto et al. (2011) avaliando a substituição parcial do farelo de soja pela ureia na dieta de vacas da raça Girolanda, encontraram resultados semelhantes aos descritos no presente estudo, especialmente para os teores de gordura $(4,99 \%)$, proteína $(3,41 \%)$ e sólidos totais $(13,81 \%)$.

Considerando-se que a produção, assim como os teores de gordura do leite não variaram em função das diferentes fontes de compostos nitrogenados na dieta de vacas $\mathrm{F} 1 \mathrm{H} / \mathrm{Z}$, pode-se inferir que o uso de ingredientes alternativos ao farelo de soja pode representar uma possibilidade para redução dos custos com alimentação.

Os teores de proteína bruta, caseína e a relação caseína/proteína do leite (Tabela 2) não foram alterados $(\mathrm{P}>0,05)$ pelas fontes de compostos nitrogenados utilizados. Entretanto houve efeito $(\mathrm{P}<0,05)$ na produção diária de proteína do leite, sendo superior para as dietas com farelo de soja e farelo de girassol. Possivelmente, esse resultado foi reflexo da maior produção e do teor mais elevado de PB dessas dietas, o que pode estar relacionado à superioridade em termos de qualidade protéica ou valor biológico da proteína desses ingredientes. Entretanto, a ausência de alteração no teor da $\mathrm{PB}$ do leite $(\mathrm{P}<0,05)$ indica que não houve limitação na proteína metabolizável com o fornecimento das dietas contendo diferentes fontes de compostos nitrogenados. Os percentuais de proteína estão acima do mínimo de $2,9 \%$ estabelecido pela IN 62 (BRASIL, 2011). 
Rev. Bras. Saúde Prod. Anim., Salvador, v.16, n.3, p.591-605 jul./set.., 2015 http://www.rbspa.ufba.br ISSN 15199940

Tabela 2. Composição físico-química do leite de vacas F1 Holandês x Zebu, ureia plasmática e produção de leite de vacas alimentadas com dietas com diferentes fontes de compostos nitrogenados, com respectivos coeficientes de variação $(\mathrm{CV})$

\begin{tabular}{lccccc}
\hline \multirow{2}{*}{ Variáveis } & \multicolumn{5}{c}{ Dietas Experimentais } \\
\cline { 2 - 6 } & Farelo de soja & Ureia & Farelo de Girassol & Farelo de mamona & CV $(\%)$ \\
\hline Gordura (\%) & $4,46^{\mathrm{a}}$ & $4,59^{\mathrm{a}}$ & $4,61^{\mathrm{a}}$ & $4,80^{\mathrm{a}}$ & 11,45 \\
Gordura (g/dia) & $796,88^{\mathrm{a}}$ & $672,64^{\mathrm{a}}$ & $749,37^{\mathrm{a}}$ & $690,17^{\mathrm{a}}$ & 19,87 \\
Proteína (\%) & $3,34^{\mathrm{a}}$ & $3,03^{\mathrm{a}}$ & $3,27^{\mathrm{a}}$ & $3,06^{\mathrm{a}}$ & 8,34 \\
Proteína (g/dia) & $650,96^{\mathrm{a}}$ & $504,58^{\mathrm{b}}$ & $593,33^{\mathrm{a}}$ & $510,41^{\mathrm{b}}$ & 16,68 \\
Lactose (\%) & $4,60^{\mathrm{a}}$ & $4,52^{\mathrm{a}}$ & $4,65^{\mathrm{a}}$ & $4,58^{\mathrm{a}}$ & 2,39 \\
Cinzas & $0,75^{\mathrm{a}}$ & $0,76^{\mathrm{a}}$ & $0,74^{\mathrm{a}}$ & $0,72^{\mathrm{a}}$ & 10,09 \\
${ }^{1} \mathrm{ST}(\%)$ & $14,11^{\mathrm{a}}$ & $14,92^{\mathrm{a}}$ & $13,36^{\mathrm{a}}$ & $13,89^{\mathrm{a}}$ & 9,78 \\
${ }^{2}$ ESD $(\%)$ & $8,94^{\mathrm{a}}$ & $8,66^{\mathrm{a}}$ & $8,96^{\mathrm{a}}$ & $8,72^{\mathrm{a}}$ & 3,1 \\
Acidez $\left({ }^{\mathrm{o}} \mathrm{D}\right)$ & $17,0^{\mathrm{a}}$ & $17,0^{\mathrm{a}}$ & $17,0^{\mathrm{a}}$ & $17,0^{\mathrm{a}}$ & 4,14 \\
Densidade (g/mL) & $1,029^{\mathrm{a}}$ & $1,029^{\mathrm{a}}$ & $1,030^{\mathrm{a}}$ & $1,029^{\mathrm{a}}$ & 0,08 \\
Crioscopia (mo H) & $-0,530^{\mathrm{a}}$ & $-0,532^{\mathrm{a}}$ & $-0,531^{\mathrm{a}}$ & $-0,532^{\mathrm{a}}$ & 0,41 \\
${ }^{3} \mathrm{CCS}(\mathrm{x} \mathrm{mil/mL)}$ & $141,1^{\mathrm{a}}$ & $144,0^{\mathrm{a}}$ & $168,38^{\mathrm{a}}$ & $158,5^{\mathrm{a}}$ & 12,10 \\
${ }^{4} \mathrm{NUL}(\mathrm{mg} / \mathrm{dL})$ & $17,81^{\mathrm{b}}$ & $24,13^{\mathrm{a}}$ & $13,15^{\mathrm{c}}$ & $14,46^{\mathrm{cb}}$ & 14,64 \\
Ureia plasmática(mg/dL) & $37,63^{\mathrm{b}}$ & $52,80^{\mathrm{a}}$ & $23,03^{\mathrm{c}}$ & $28,95^{\mathrm{c}}$ & 13,95 \\
Caseína (\%) & $2,47^{\mathrm{a}}$ & $2,18^{\mathrm{a}}$ & $2,42^{\mathrm{a}}$ & $2,23^{\mathrm{a}}$ & 9,66 \\
Caseína (\%Proteína) & $76,36^{\mathrm{a}}$ & $62,71^{\mathrm{a}}$ & $73,85^{\mathrm{a}}$ & $72,91^{\mathrm{a}}$ & 17,5 \\
Caseína/proteína & $0,76^{\mathrm{a}}$ & $0,72^{\mathrm{a}}$ & $0,74^{\mathrm{a}}$ & $0,73^{\mathrm{a}}$ & 4,9 \\
Produção leite (Kg) & $18,12^{\mathrm{a}}$ & $17,36^{\mathrm{a}}$ & $18,62^{\mathrm{a}}$ & $17,20^{\mathrm{a}}$ & 6,83 \\
${ }^{5}$ PLCG (Kg) & $20,16^{\mathrm{a}}$ & $20,25^{\mathrm{a}}$ & $20,55^{\mathrm{a}}$ & $19,31^{\mathrm{a}}$ & 10,31 \\
\hline
\end{tabular}

Médias Seguidas de letras diferentes na linha diferem entre si $(\mathrm{P}<0,05)$, pelo Teste de Tukey.

${ }^{1}$ Teor de Sólidos Totais, ${ }^{2}$ Teor de Extrato Seco Desengordurado, ${ }^{3}$ Contagem de Células Somáticas,

${ }^{4}$ Nitrogênio Ureico no leite, ${ }^{5}$ Produção de leite ajustada para 3,5\% gordura.

Os valores de proteína do leite são importantes, principalmente a caseína, pois tais concentrações afetam diretamente, diminuindo ou aumentando o rendimento de derivados do leite. Aquino et al. (2009) verificaram que a adição de até $1,5 \%$ de ureia, substituindo parcialmente o farelo de soja na dieta de vacas no terço médio da lactação, com produção média de $22,77 \mathrm{~kg}$ de leite dia $^{-1}$, não altera o teor de proteína do leite e a capacidade de produção de proteína microbiana no rúmen, atendendo às necessidades de proteína metabolizável da vaca. Porém Broderick et al. (2009) trabalhando com vacas de alta produção, $40,0 \mathrm{~kg}$ de leite $\mathrm{dia}^{-1}$, encontraram resultados diferentes, mostrando que a substituição da proteína degradável no rúmen do farelo de soja pela ureia diminuiu a produção e os demais componentes do leite, provavelmente pela redução na produção de proteína microbiana no rúmen e que quando utiliza-se fontes de NNP como fontes de PDR a mesma não é tão eficiente como as fontes de proteína verdadeira para otimizar a produção de proteína microbiana. Enquanto que Pereira et al. (2011) avaliando quatro níveis de inclusão de torta de girassol, $0,7,14$ e $21 \%$, na dietas de vacas em lactação da raça Girolanda, verificaram efeito linear decrescente para os teores de proteína do leite, com redução média de 0,11 unidades percentuais, e nos teores gordura do leite, de 0,1 a 0,3 unidades 
Rev. Bras. Saúde Prod. Anim., Salvador, v.16, n.3, p.591-605 jul./set.., 2015 http://www.rbspa.ufba.br

percentuais, com a inclusão de torta de girassol.

Os teores de sólidos totais não foram influenciados pelas fontes de compostos nitrogenados utilizados $(\mathrm{P}>0,05)$ (Tabela 2). Esta variável é uma importante indicadora da qualidade do leite representada pela soma de todas as partes sólidas do leite, principalmente gorduras e proteínas, consideradas, na indústria de lacticínios, como os componentes que promovem $\mathrm{o}$ rendimento em produtos oriundos do leite, e por meio dos quais se faz o pagamento ao produtor pelo produto entregue à indústria.

Semelhante aos resultados deste trabalho, Neto et al. (2013) avaliando duas fontes de NNP, ureia tradicional e OptigenII ${ }^{\circledR}$, na dieta de vacas mestiças Holândes/Zebu, oferecidas em três níveis, 0,$3 ; 0,6$ e $0,9 \%$, na matéria natural e uma dieta controle sem fonte de NNP, não encontraram diferença nos teores de sólidos totais, com média de $11,19 \%$.

Os percentuais de resíduo mineral fixo, extrato seco desengordurado (ESD) e lactose também não foram influenciados ( $p>0,05)$ pelas diferentes fontes de compostos nitrogenados nas dietas das vacas (Tabela 2), verificando-se valores médios de 0,$74 ; 8,82$ e 4,59\%, respectivamente. O valor do ESD está nos limites mínimos preconizados pela legislação de 8,4\% (BRASIL, 2011). De forma similar a este trabalho, Neto et al. (2013) também não verificaram diferença no $\operatorname{ESD}(8,17 \%)$ do leite de vacas mestiças suplementadas com diferentes fontes de NNP.

Verificou-se neste trabalho que não houve influência das dietas $(\mathrm{P}>0,05)$ em relação à acidez, densidade, índice crioscópio, apresentando valores médios $17^{\circ} \mathrm{D} ; \quad 1,029 \mathrm{~g} / \mathrm{mL}$ e $0,53^{\circ} \mathrm{H}$, respectivamente. Esses valores estão dentro dos requisitos mínimos de qualidade para o leite cru de uso industrial conforme Instrução Normativa $\mathrm{N}^{\circ} 62$ que preconiza valores de 1,028 a $1,034 \mathrm{~g} / \mathrm{mL}$ para densidade; 14 a $18^{\circ} \mathrm{D}$ (acidez titulável); e - 0,560 a - $0,530^{\circ} \mathrm{H}$ para índice crioscópico (BRASIL, 2011).

$\mathrm{O}$ teor de nitrogênio uréico no leite (NUL) foi influenciado pelas fontes de compostos nitrogenados na dieta das vacas $(\mathrm{P}<0,05)$, sendo o maior valor encontrado (Tabela 2) no leite dos animais com ureia na dieta $(24,13 \mathrm{mg} / \mathrm{dL})$, seguido pelo farelo de soja $(17,81 \mathrm{mg} / \mathrm{dL})$ que por sua vez foi superior aos farelos de girassol e mamona detoxificado $(13,15$ e $14,46 \mathrm{mg} / \mathrm{dL}$, respectivamente), provavelmente, em função das diferenças na degradabilidade ruminal das fontes de compostos nitrogenados avaliadas. Os níveis normalmente aceitos de NUL estão entre 12 a $18 \mathrm{mg} / \mathrm{dL}$, equivalentes a $25,7 \mathrm{a}$ $38,5 \mathrm{mg} / \mathrm{dL}$ de ureia $(1 \mathrm{~mol}$ de $\mathrm{NUL}=2,14$ móis de ureia). O NUL elevado, como é o caso da dieta com ureia, pode indicar que houve excesso de nitrogênio degradável no rúmen, além da capacidade dos microrganismos ruminais utilizarem na síntese de proteína microbiana, ou que a disponibilidade de energia no rúmen não foi adequada à quantidade de ureia ingerida pelos animais. Ressalta-se que, segundo Sartori \& Guardieiro (2010), a utilização de altos teores de proteína ou NNP na dieta apresenta aspectos negativos à reprodução, pois elevam as concentrações plasmáticas de ureia e amônia, diminuindo o pH luminal uterino durante a fase lútea inicial e alteram a secreção das glândulas endometriais. Além disso, de acordo com Aquino et al. (2009), a utilização de nitrogênio não protéico (NNP) pode alterar a composição da proteína do leite, influenciando $\mathrm{o}$ processamento industrial da matéria prima, já que os teores de proteína verdadeira e da 
Rev. Bras. Saúde Prod. Anim., Salvador, v.16, n.3, p.591-605 jul./set.., 2015 http://www.rbspa.ufba.br

caseína têm influência direta sobre a fabricação de queijo.

A ureia plasmática apresentou o mesmo comportamento do NUL, com valores mais altos na dieta com ureia. Chizzotti et al. (2007) confirmam a alta correlação do NUL e NUP. Entretanto, deve-se destacar que a elevação do NUL na dieta com ureia, com produção média de $20 \mathrm{Kg}$ de leite com $3,5 \%$ de gordura, não foi acompanhada por redução dos teores de caseína $(\mathrm{P}>0,05)$ no leite, sugerindo que essa dieta atendeu às necessidades de aminoácidos para síntese de caseína pela glândula mamária.

Para Aquino et al. (2007), os níveis de ureia da dieta não influenciaram a concentração de NUL, sendo observadas médias de 17,97; 17,28 e $16,59 \mathrm{mg} / \mathrm{dL}$ com as dietas com 0, 0,75 e $1,5 \%$ de ureia, respectivamente, utilizando $60 \%$ de concentrado nas dietas, enquanto que neste trabalho a proporção de concentrado foi de $30 \%$ da matéria seca fornecida.

O menor valor de NUL desta pesquisa na dieta com farelo de girassol, em relação às dietas com ureia e farelo de soja, corrobora com os resultados encontrados por Pereira et al. (2011), que ao avaliarem quatro níveis de inclusão de torta de girassol, $0 ; 7 ; 14 \mathrm{e}$ $21 \%$, na dieta de vacas em lactação da raça Girolanda, observaram efeito linear decrescente para as concentrações de NUL, o que pode sugerir uma melhor sincronização entre a taxa de degradação de carboidratos e proteína no rúmen.

A CCS foi menor que 200.000 células $/ \mathrm{mL}$ em todos os tratamentos e não diferiu $(\mathrm{P}>0,05)$ entre os mesmos.

Conforme pode ser observado na Tabela 3 , foram identificados e quantificados 20 ácidos graxos saturados (AGS), 15 ácidos graxos monoinsaturados (AGM), e 6 ácidos graxos poliinsaturados (AGPI). Não houve efeito significativo $(\mathrm{P}>0,05)$ em relação às dietas experimentais nos somatórios dos AGS, AGM e AGPI, perfazendo médias de $77,2,20,38$ e $1,36 \%$, respectivamente.

$\mathrm{O}$ ácido butírico (C4:0) no leite foi menor $(\mathrm{P}<0,05)$ para dieta com farelo de soja em relação às demais dietas. Já para os ácidos C10:1 e C12:1 foi encontrado concentrações superiores no leite, para as dietas com farelo de soja e farelo de girassol. $O$ aumento da proporção dos AG de cadeias curta e média pode ser decorrente do aumento de precursores da síntese de novo, acetato e $\beta$-hidroxibutirato, resultantes da fermentação ruminal, e a diminuição pela direta inibição do complexo enzimático envolvido na síntese de novo pela ação dos ácidos graxos de cadeia longa dos óleos vegetais (NUDDA et al., 2014). Conforme pode ser visualizado na tabela 1 , os teores de extrato etéreo nas quatro dietas experimentais ficaram abaixo de $2,5 \%$ da MS, indicando que esta fração não seria a responsável por possíveis alterações no perfil da fermentação ruminal. Uma hipótese para alteração no perfil lipídico do leite de vacas alimentadas com dietas contendo diferentes fontes de compostos nitrogenados seria uma possível alteração no equilíbrio da microbiota ruminal e consequentemente do perfil da fermentação e do conteúdo que chega ao duodeno. Segundo Benchaar et al. (2007), o perfil de ácidos graxos no leite pode ser alterado por modificações no padrão de fermentação ruminal e espécies de bactérias ruminais e de acordo com Vlaeminck et al. (2006), parte dos ácidos graxos que compõem a gordura do leite vêm da absorção intestinal de lipídeos de membrana provenientes das bactérias do rumem. 
Rev. Bras. Saúde Prod. Anim., Salvador, v.16, n.3, p.591-605 jul./set.., 2015 http://www.rbspa.ufba.br ISSN 15199940

Tabela 3. Perfil de ácidos graxos da gordura do leite de vacas F1 Holândes/Zebu alimentadas com dietas com diferentes fontes de compostos nitrogenados

\begin{tabular}{|c|c|c|c|c|c|c|}
\hline \multirow[b]{2}{*}{ Componentes } & \multicolumn{4}{|c|}{ Dietas Experimentais } & \multirow[b]{2}{*}{$\begin{array}{l}\mathrm{CV} \\
(\%)\end{array}$} & \multirow[b]{2}{*}{$\operatorname{Pr}>\mathrm{Fc}$} \\
\hline & $\begin{array}{l}\text { Farelo de } \\
\text { soja }\end{array}$ & Ureia & $\begin{array}{l}\text { Farelo de } \\
\text { Girassol }\end{array}$ & $\begin{array}{l}\text { Farelo de mamona } \\
\text { detoxificado }\end{array}$ & & \\
\hline Saturados & $78,5^{\mathrm{a}}$ & $76,0^{\mathrm{a}}$ & $77,0^{\mathrm{a}}$ & $77,5^{\mathrm{a}}$ & 5,6 & 0,7175 \\
\hline $\mathrm{C} 4: 0$ & $1,85^{\mathrm{b}}$ & $2,91^{\mathrm{a}}$ & $2,68^{\mathrm{a}}$ & $2,81^{\mathrm{a}}$ & 27,2 & 0,0234 \\
\hline C6:0 & $1,76^{\mathrm{a}}$ & $1,94^{\mathrm{a}}$ & $2,09^{\mathrm{a}}$ & $1,96^{\mathrm{a}}$ & 20 & 0,4254 \\
\hline $\mathrm{C} 8: 0$ & $1,28^{\mathrm{a}}$ & $1,27^{\mathrm{a}}$ & $1,39^{\mathrm{a}}$ & $1,26^{\mathrm{a}}$ & 15,8 & 0,5864 \\
\hline C10:0 & $1,92^{\mathrm{a}}$ & $1,61^{\mathrm{a}}$ & $2,04^{\mathrm{a}}$ & $1,78^{\mathrm{a}}$ & 23,3 & 0,2453 \\
\hline C10:1 & $0,33^{\mathrm{a}}$ & $0,32^{\mathrm{a}}$ & $0,34^{\mathrm{a}}$ & $0,29^{\mathrm{a}}$ & 19,0 & 0,4776 \\
\hline C11:0 & $3,54^{\mathrm{a}}$ & $3,00^{\mathrm{a}}$ & $3,64^{\mathrm{a}}$ & $3,10^{\mathrm{a}}$ & 20,4 & 0,1764 \\
\hline $\mathrm{C} 12: 0$ & $0,02^{\mathrm{a}}$ & $0,02^{\mathrm{a}}$ & $0,02^{\mathrm{a}}$ & $0,02^{\mathrm{a}}$ & 19,8 & 0,2135 \\
\hline C13:0 ISSO & $0,09^{\mathrm{a}}$ & $0,07^{\mathrm{a}}$ & $0,08^{\mathrm{a}}$ & $0,07^{\mathrm{a}}$ & 24,7 & 0,2411 \\
\hline C13:0 ANTEISO & $0,10^{\mathrm{a}}$ & $0,08^{\mathrm{a}}$ & $0,10^{\mathrm{a}}$ & $0,07^{\mathrm{a}}$ & 25,4 & 0,1351 \\
\hline C13:00 & $0,10^{\mathrm{a}}$ & $0,13^{\mathrm{a}}$ & $0,12^{\mathrm{a}}$ & $0,12^{\mathrm{a}}$ & 26,2 & 0,2637 \\
\hline C14:0 ISSO & $13,15^{\mathrm{a}}$ & $11,88^{\mathrm{a}}$ & $12,71^{\mathrm{a}}$ & $12,11^{\mathrm{a}}$ & 11,04 & 0,2659 \\
\hline $\mathrm{C} 14: 0$ & $0,21^{\mathrm{a}}$ & $0,19^{\mathrm{a}}$ & $0,22^{\mathrm{a}}$ & $0,22^{\mathrm{a}}$ & 18,9 & 0,5568 \\
\hline C15:0 ISSO & $0,29^{\mathrm{a}}$ & $0,35^{\mathrm{a}}$ & $0,33^{\mathrm{a}}$ & $0,31^{\mathrm{a}}$ & 18,7 & 0,2795 \\
\hline C15:0 ANTEISO & $1,08^{\mathrm{a}}$ & $1,13^{\mathrm{a}}$ & $1,11^{\mathrm{a}}$ & $1,01^{\mathrm{a}}$ & 18,3 & 0,6649 \\
\hline $\mathrm{C} 15: 0$ & $0,14^{\mathrm{a}}$ & $0,19^{\mathrm{a}}$ & $0,18^{\mathrm{a}}$ & $0,17^{\mathrm{a}}$ & 29,6 & 0,1667 \\
\hline C16:0 & $0,13^{\mathrm{a}}$ & $0,11^{\mathrm{a}}$ & $0,13^{\mathrm{a}}$ & $0,13^{\mathrm{a}}$ & 24,1 & 0,5820 \\
\hline C17:00 ISSO & $1,22^{\mathrm{a}}$ & $1,34^{\mathrm{a}}$ & $1,13^{\mathrm{a}}$ & $1,33^{\mathrm{a}}$ & 26,6 & 0,5723 \\
\hline C17:00 & $0,43^{\mathrm{a}}$ & $0,36^{\mathrm{a}}$ & $0,38^{\mathrm{a}}$ & $0,39^{\mathrm{a}}$ & 24,6 & 0,5115 \\
\hline C18:00 & $10,22^{\mathrm{a}}$ & $10,31^{\mathrm{a}}$ & $10,58^{\mathrm{a}}$ & $8,61^{\mathrm{b}}$ & 13,4 & 0,0298 \\
\hline $\mathrm{C} 20: 0$ & $0,01^{\mathrm{a}}$ & $0,02^{\mathrm{a}}$ & $0,01^{\mathrm{a}}$ & $0,02^{\mathrm{a}}$ & 49,8 & 0,6452 \\
\hline Monoinsaturados & $19,09^{\mathrm{a}}$ & $21,73^{\mathrm{a}}$ & $20,50^{\mathrm{a}}$ & $20,18^{\mathrm{a}}$ & 19,1 & 0,6101 \\
\hline C10:1 & $0,06^{\mathrm{a}}$ & $0,03^{\mathrm{b}}$ & $0,06^{\mathrm{a}}$ & $0,04^{\mathrm{b}}$ & 38,4 & 0,0142 \\
\hline C12:1 & $0,14^{\mathrm{a}}$ & $0,10^{\mathrm{b}}$ & $0,15^{\mathrm{a}}$ & $0,12^{\mathrm{b}}$ & 24,1 & 0,0117 \\
\hline C14:1 C9 & $1,16^{\mathrm{a}}$ & $0,94^{\mathrm{a}}$ & $1,10^{\mathrm{a}}$ & $1,13^{\mathrm{a}}$ & 16,7 & 0,1065 \\
\hline C15:1 & $41,92^{\mathrm{a}}$ & $40,52^{\mathrm{a}}$ & $39,02^{\mathrm{a}}$ & $43,07^{\mathrm{a}}$ & 10,9 & 0,3223 \\
\hline C16:1 C9 & $0,43^{\mathrm{a}}$ & $0,36^{\mathrm{a}}$ & $0,38^{\mathrm{a}}$ & $0,39^{\mathrm{a}}$ & 24,6 & 0,5215 \\
\hline $\mathrm{C} 17: 1$ & $0,09^{\mathrm{a}}$ & $0,11^{\mathrm{a}}$ & $0,11^{\mathrm{a}}$ & $0,12^{\mathrm{a}}$ & 26,4 & 0,1775 \\
\hline C18:1 T6-T7-T8-T9 & $0,26^{\mathrm{a}}$ & $0,26^{\mathrm{a}}$ & $0,31^{\mathrm{a}}$ & $0,31^{\mathrm{a}}$ & 28,7 & 0,4598 \\
\hline C18:1 T10-T11-T12 & $0,62^{\mathrm{b}}$ & $0,60^{\mathrm{b}}$ & $0,77^{\mathrm{a}}$ & $0,84^{\mathrm{a}}$ & 26,6 & 0,0102 \\
\hline C18:1 C9 & $13,09^{\mathrm{a}}$ & $15,32^{\mathrm{a}}$ & $14,35^{\mathrm{a}}$ & $13,92^{\mathrm{a}}$ & 14,2 & 0,5062 \\
\hline C18:1 C12 & $0,60^{\mathrm{a}}$ & $0,62^{\mathrm{a}}$ & $0,56^{\mathrm{a}}$ & $0,55^{\mathrm{a}}$ & 28,5 & 0,8163 \\
\hline C18:1 C13 & $0,27^{\mathrm{a}}$ & $0,33^{\mathrm{a}}$ & $0,29^{\mathrm{a}}$ & $0,29^{\mathrm{a}}$ & 24,2 & 0,4358 \\
\hline C18:1 T16 & $0,12^{\mathrm{a}}$ & $0,12^{\mathrm{a}}$ & $0,13^{\mathrm{a}}$ & $0,12^{\mathrm{a}}$ & 20,2 & 0,6955 \\
\hline C18:1 C11 & $1,25^{\mathrm{a}}$ & $1,43^{\mathrm{a}}$ & $1,25^{\mathrm{a}}$ & $1,26^{\mathrm{a}}$ & 29,7 & 0,7410 \\
\hline C18:1 C15 & $0,04^{\mathrm{a}}$ & $0,04^{\mathrm{a}}$ & $0,04^{\mathrm{a}}$ & $0,05^{\mathrm{a}}$ & 28,5 & 0,6576 \\
\hline $\mathrm{C} 24: 1$ & $0,05^{\mathrm{a}}$ & $0,05^{\mathrm{a}}$ & $0,05^{\mathrm{a}}$ & $0,05^{\mathrm{a}}$ & 19,3 & 0,9487 \\
\hline Poliinsaturados & $1,42^{\mathrm{a}}$ & $1,29 a$ & $1,32^{\mathrm{a}}$ & $1,44^{\mathrm{a}}$ & 23,5 & 0,4070 \\
\hline C18:2 C9 C12 & $0,76^{\mathrm{a}}$ & $0,62^{\mathrm{a}}$ & $0,63^{\mathrm{a}}$ & $0,64^{\mathrm{a}}$ & 31,3 & 0,2069 \\
\hline C18:3 n6 & $0,12^{\mathrm{a}}$ & $0,11^{\mathrm{a}}$ & $0,12^{\mathrm{a}}$ & $0,10^{\mathrm{a}}$ & 21,2 & 0,3111 \\
\hline C18:3 n3 & $0,12^{\mathrm{a}}$ & $0,11^{\mathrm{a}}$ & $0,12^{\mathrm{a}}$ & $0,09^{\mathrm{a}}$ & 21,2 & 0,1138 \\
\hline C18:2 C9 T 11 (CLA) & $0,27^{\mathrm{a}}$ & $0,26^{\mathrm{a}}$ & $0,30^{\mathrm{a}}$ & $0,37^{\mathrm{a}}$ & 32,7 & 0,1635 \\
\hline $\mathrm{C} 20: 5$ & $0,01^{\mathrm{a}}$ & $0,01^{\mathrm{a}}$ & $0,01^{\mathrm{a}}$ & $0,01^{\mathrm{a}}$ & 35,8 & 0,2635 \\
\hline
\end{tabular}


A dieta afetou $(\mathrm{P}<0,05)$ as concentrações do isômero C18:1 T10 - T11-T12 no leite, sendo superior quando farelo de girassol e farelo de mamona detoxificado foram utilizados. Segundo Moallem (2009), o acúmulo de trans-C18:1 no leite é característica de incompleta biohidrogenação dos ácidos graxos no rúmen. Esse autor observou um aumento no teor de isômeros trans do ácido graxo 18:1 no leite de animais que receberam dieta com grão de linhaça extrusada. Isômeros específicos de 18:1 trans podem estar relacionados com a diminuição da síntese de novo na glândula mamária.

Os isômeros trans- 10 , trans- 11 , trans- 12 C18:1 foram mais altos no leite de vacas alimentadas com as dietas com farelo de girassol e farelo de mamona detoxificado, o que pode sugerir a possibilidade de diferentes rotas de biohidrogenação. De acordo com Loor \& Herbein (2003), trans-6-8 e trans-9 C18:1 são os principais intermediários durante a isomerização do ácido oléico (cis-9 C18:1) e intermediários menores da biohidrogenação do ácido linolênico. Mosley et al. (2002) verificaram que o ácido oléico não é reduzido diretamente ao esteárico (C18:0), mas parte é isomerizada a trans -9 , trans-10, trans -11 ou trans-12 C18:1 antes de sua completa saturação.

$\mathrm{O}$ ácido linoléico conjugado CLA (C18: 2 cis-9 trans-11) no leite não sofreu influência $(\mathrm{P}>0,05)$ das dietas com diferentes fontes de compostos nitrogenados. O CLA origina-se a partir da biohidrogenação dos ácidos linoléico e linolênico e a partir da dessaturação do ácido trans-vacénico (C18 : 1 trans-11) na glândula mamária (CASTRO et al., 2009). O teor deste ácido graxo no leite pode ser alterado por modificações no padrão de fermentação ruminal, espécies de bactérias ruminais e suplementação de CLA e trans-11 C18:1 na dieta (BENCHAAR et al., 2007).

Entre os AGM, o maior percentual encontrado foi do ácido oléico. Esse ácido graxo é um produto da atividade da enzima $\Delta^{9}$ - dessaturase responsável pela dessaturação de AGS com 14 a 18 átomos de carbono, convertendo-os em seus correspondentes monoinsaturados com uma ligação dupla no carbono 9 (MOSLEY et al., 2002).

Houve diferença $(\mathrm{P}<0,05)$ na concentração do ácido esteárico (C18:0), encontrando-se maiores concentrações no leite de vacas alimentadas com as dietas contendo farelo de soja, ureia e farelo de girassol. A hipótese é que as dietas supracitadas podem modificar o perfil de ácidos graxos do leite aumentando a hidrogenação do ácido linoléico (C18:2) e linolênico (C18:3), que são os principais substratos para biohidrogenação encontrados nas forragens e grãos das dietas de ruminantes. A completa biohidrogenação desses ácidos resulta na síntese de ácido esteárico (C18:0), fazendo com que ele seja o $\mathrm{AG}$ de maior concentração no líquido que fluido de rúmen e, consequentemente, na digesta que chega ao duodeno. Pode-se esperar que entre 60 a $85 \%$ das gorduras insaturadas sejam biohidrogenadas no rúmen, permitindo que de 15 a $40 \%$ destas fluam para a absorção no intestino delgado, podendo ser incorporadas no tecido e leite (LOCK \& BAUMAN, 2011).

Como nas dietas experimentais utilizouse o farelo de mamona detoxificado, que originalmente tem os princípios tóxicos ricina e ricinina, os quais podem trazer sérios prejuízos para produção animal, tentou-se identificar o ácido ricinoléico, mas não observou-se a presença do mesmo, mostrando que o processo de detoxificação com 
Rev. Bras. Saúde Prod. Anim., Salvador, v.16, n.3, p.591-605 jul./set.., 2015 http://www.rbspa.ufba.br ISSN 15199940

hidróxido de cálcio, $\mathrm{Ca}(\mathrm{OH})_{2}$, foi eficiente.

Os índices de aterogenicidade (IA), trombogenecidade (IT), a relação hiper/hipocolesterol, ácidos graxos desejáveis, assim como a relação ácidos graxos poli-insaturados/ácidos graxos saturados (AGP/AGS) não tiveram diferenças significativas $(\mathrm{P}>0,05) \quad \mathrm{em}$ relação às dietas com diferentes fontes de compostos nitrogenados (Tabela 4).
Os valores médios encontrados neste trabalho para a composição de ácidos graxos desejáveis (Tabela 4) foram de $30,31 \%$. Os ácidos graxos saturados (AGS) têm a capacidade de elevar os níveis de LDL (lipoproteína de baixa densidade) e reduzir os níveis de HDL (lipoproteína de alta densidade), o que contribui para a elevação dos riscos de doença coronariana (SOFI et al., 2010).

Tabela 4. Índice de Aterogenecidade, Índice de Trombogenecidade, Relação Hiper/Hipocolesterolêmicos, Ácidos Graxos Desejáveis, Relação de Ácidos Graxos Poliinsaturados/Ácidos Graxos Saturados e Relação ômega-3/ômega-6 do leite de vacas F1 Holandês x Zebu alimentadas com dietas com diferentes fontes de compostos nitrogenados

\begin{tabular}{lccccc}
\hline \multirow{2}{*}{ Variáveis } & \multicolumn{4}{c}{ Dietas Experimentais } & \\
\cline { 2 - 4 } & $\begin{array}{c}\text { Farelo de } \\
\text { soja }\end{array}$ & Ureia & $\begin{array}{c}\text { Farelo de } \\
\text { Girassol }\end{array}$ & $\begin{array}{c}\text { Farelo de } \\
\text { mamona }\end{array}$ & CV (\%) \\
\hline Aterogenecidade & $6,39^{\mathrm{a}}$ & $5,07^{\mathrm{a}}$ & $5,54^{\mathrm{a}}$ & $5,66^{\mathrm{a}}$ & 18,56 \\
Trombogenecidade & $9,07^{\mathrm{a}}$ & $7,30^{\mathrm{a}}$ & $7,74^{\mathrm{a}}$ & $7,95^{\mathrm{a}}$ & 23,68 \\
Hiper/Hipocolesterolêmicos & $2,93^{\mathrm{a}}$ & $2,33^{\mathrm{a}}$ & $2,42^{\mathrm{a}}$ & $2,67^{\mathrm{a}}$ & 28,49 \\
AG Desejáveis & $29,32^{\mathrm{a}}$ & $32,03^{\mathrm{a}}$ & $31,07^{\mathrm{a}}$ & $28,79^{\mathrm{a}}$ & 13,06 \\
AGP/AGS & $0,02^{\mathrm{a}}$ & $0,02^{\mathrm{a}}$ & $0,02^{\mathrm{a}}$ & $0,02^{\mathrm{a}}$ & 28,57 \\
$\omega 6 / \omega 3$ & $2,14^{\mathrm{b}}$ & $2,48^{\mathrm{b}}$ & $2,55^{\mathrm{b}}$ & $3,54^{\mathrm{a}}$ & 28,88 \\
\hline
\end{tabular}

Médias seguidas de mesma letra nas linhas, não diferem entre si pelo teste de Tukey ao nível de $5 \%$ de significância.

Os ácidos graxos dessa classe, que apresentam maior poder hipercolesterolêmico ou aterogênico, são os ácidos mirístico (14:0), palmítico $(16: 0)$ e láurico (12:0), em ordem decrescente de atividade. Já o ácido esteárico (18:0), apesar de saturado, parece não ter efeito sobre as lipoproteínas do sangue (SOFI et al., 2010).

A relação $\omega 6 / \omega 3$ foi alterada significativamente $(p<0,05)$ pela fonte de composto nitrogenado utilizada (Tabela 4), verificando-se a maior relação para a dieta com farelo de mamona detoxificado $(3,54)$. A relação $\omega-6: \omega-3$ é um importante parâmetro utilizado para classificar a qualidade nutricional das gorduras, óleos, alimentos e dietas. Dietas com relações entre 2:1 e 3:1 têm sido as mais recomendadas, por possibilitar maior conversão do ácido $\alpha$-linolênico a ácido docosahexaenoico (DHA, C22:6 cis-4 cis-7 cis- 10 cis-13 cis-16 cis-19), alcançando valores máximos em torno de 2,3:1 (MARTIN et al., 2006). Na gordura do leite, essa relação tende a ser mais alta, sendo influenciada pelo regime alimentar, permitindo que alguns produtos de ruminantes se tornem importantes fontes de AG $\omega-3$ na dieta humana (HAUG et al., 2007). O aumento da relação $\omega-6: \omega-3$ é indesejável do ponto de vista de saúde humana já que, apesar do AG $\omega-6$ ser 
Rev. Bras. Saúde Prod. Anim., Salvador, v.16, n.3, p.591-605 jul./set.., 2015 http://www.rbspa.ufba.br ISSN 15199940

considerado essencial, níveis elevados do mesmo podem ser responsáveis por desencadear uma série de disfunções fisiológicas, como a formação de trombos, de ateromas e de desordens imunológicas (MARTIN et al., 2006). $\mathrm{O}$ uso de dietas com diferentes fontes de compostos nitrogenados para vacas $\mathrm{F} 1$ Holandês/Zebu não altera a composição físico-química do leite, com exceção do nitrogênio uréico que aumenta na dieta com ureia, sem reduzir o teor de caseína. Entretanto, pode modificar o perfil de ácidos graxos da gordura do leite.

\section{AGRADECIMENTOS}

Ao BNB/FUNDECI pelo auxilio financeiro; $A$ FAPEMIG, CNPq e CAPES pelo auxílio com bolsas; A Fazenda Experimental de Felixlândia/EPAMIG.

\section{REFERÊNCIAS}

ANANDAN, S.; ANIL KUMAR, G.K.; GHOSH, J.; RAMACHANDRA, K.S. Effect of different physical and chemical treatments on detoxification of ricin in castor cake. Animal Feed Science and Technology, v.120, p.159168, 2005.

AQUINO, A.A.; BOTARO, B.G.; IKEDA, F.S.; RODRIGUES, P.H.M.; MARTINS, M.F.; SANTOS, M.V.

Efeito de níveis crescentes de ureia na dieta de vacas em lactação sobre a produção e a composição físico-química do leite. Revista Brasileira de Zootecnia, V.36, n. 4, p. 881-887, 2007.
AQUINO, A.A.; PEIXOTO JUNIOR, K.C.; GIGANTE, M.L. Efeito de níveis crescentes de ureia na dieta de vacas leiteiras sobre a composição e rendimento de fabricação de queijos de minas frescal.

Brazilian Journal of Veterinary

Research and Animal Science, v.46, n.4, p.273-279, 2009.

BENCHAAR, C.; PETIT, H.V.;

BERTHIAUME, R.; OUELLET, D.R.; CHIQUETTE, J.; CHOUINARD, P.Y. Effects of essential oils on digestion, ruminal fermentation, rumen microbial populations, milk production, and milk composition in dairy cows fed alfalfa silage or corn silage. Journal of Dairy Science, v.90, p.886-897, 2007.

BRASIL. Instrução Normativa $n^{0}$ 62, de 29 de dezembro de 2011. Aprova o Regulamento Técnico de Identidade e Qualidade do Leite Cru Refrigerado. Diário Oficial da União, Brasília, DF, 30 dez. de 2011. Seção 1.

BRASIL. Ministério da Agricultura, Pecuária e Abastecimento. Métodos Analíticos Oficiais Físico-Químicos para Controle de Leite e Produtos Lácteos. Instrução Normativa $n^{\circ} .22$ de 14 de dezembro de 2006. Diário Oficial da União, Brasília, DF, 2006. Disponível em: <http://www.agricultura.gov.br $>$. Acesso em: 10 jan. 2014.

BRODERICK, G.A.; REYNAL, S.M. Effect of source of rumen-degraded protein on production and ruminal metabolism in lactating dairy cows. Journal of Dairy Science, v.92, p.28222834, 2009.

CASTRO, T.; MANSO, T.; JIMENO, V.; DEL ALAMO, M.; MANTECÓN, A.R. Effects of dietary sources of vegetable fats on performance of dairy ewes and conjugated linoleic acid (CLA) in milk. Small Ruminant Research, v.84, p.4753, 2009. 
Rev. Bras. Saúde Prod. Anim., Salvador, v.16, n.3, p.591-605 jul./set.., 2015 http://www.rbspa.ufba.br ISSN 15199940

CHIZZOTTI, M.L.; VALADARES

FILHO, S.C.; VALADARES R.F.D.; CHIZZOTTI F.H.M.; MARCONDES M.I.; FONSECA M.A. Intake, digestibility and nitrogen metabolism in holstein cows with different milk production levels. Revista Brasileira de Zootecnia, v.36, p.138-146, 2007.

COSTA, R.G.; MESQUITA, Í.V.U.; EGYPTO, R.C.R.Q.; MEDEIROS, A.N.; CARVALHO, F.F.R.; BELTRÃO FILHO E.M. Características químicas e sensoriais do leite de cabras Moxotó alimentadas com silagem de maniçoba. Revista Brasileira de Zootecnia, v.37, n.4, p.694-702, 2008.

DETMANN, E.; SOUZA, M.A.; VALADARES FILHO, S.C.; QUEIROZ, A.C.; BERCHIELLI, T.T.; SALIBA, E.O.S.; CABRAL, L.S.; PINA, D.S.; LADEIRA, M.M.; AZEVEDO, J.A.G. Métodos para análise de alimentos: INCT: Ciência Animal. Visconde do Rio Branco: Suprema, 2012. 214p.

FERREIRA, D.F. SISVAR: A computer statistical analysis system. Ciência e Agrotecnologia, v.35, n.6, p.10391042, 2011.

FREITAS JÚNIOR, J.E.de; ROCHA JÚNIOR, V.R.; RENNÓ, F.P.; MELO, M.T.P.de; CARVALHO, A.P.de; CALDEIRA, L.A. Efeito da condição corporal ao parto sobre o desempenho produtivo de vacas mestiças Holandês $\times$ Zebu. Revista Brasileira de Zootecnia, v.37, n.1, p.116-121, 2008.

HAUG, A.; HØSTMARK, A. T.; HARSTAD, O. M. Bovine milk in human nutrition - a review. Lipids in Health and Disease, v.6, p.25, 2007.
HOJMAN, D.; GIPS, M.; EZRA, E. Association between live body weight and milk urea concentration in Holstein cows. Journal of Dairy Science, v.88, p.580-584, 2005.

KROLOW, R.H.; SILVA, M.A.; PAIM, N.R. ; MEDEIROS, R.B.; GONZALEZ, H.L. Composição do leite de vacas Holandesas em pastejo de azevém com a utilização do trevo branco como fonte protéica. Arquivo Brasileiro de Medicina Veterinária e Zootecnia, v.64, n.5, p.1352-1359, 2012.

LOCK, A.L.; BAUMAN, D.E. Separating Milk Fats from Fiction. WCDS Advances in Dairy Technology, v.23, p.19-36, 2011.

LOOR, J.J.; HERBEIN, J.H. Reduced fatty acids synthesis and desaturation due to exogenous trans-10, cis-12-CLA in cows fed oleic or linoleic oil. Journal of Dairy Science, v.86, p.1354-1369, 2003.

MARTIN, C.A.; ALMEIDA, V.V.; RUIZ, M.R.; VISENTAINER, J.E.L.; MATSHUSHITA, M.; SOUZA, N.E.; VISENTAINER, J.V. Ácidos graxos poliinsaturados ômega-3 e ômega-6: importância e ocorrência em alimentos. Revista Nutrição, v.19, p.761-770, 2006.

MOALLEM, U. The effects of extruded flaxseed supplementation to high-yielding dairy cows on milk production and milk fatty acid composition. Animal Feed Science and Technology, v.152, p.232242, 2009.

MOSLEY, E.E.; POWELL, G.L.; RILEY, M.B.; JENKINS, T.C. Microbial biohydrogenation of oleic acid to trans isomers in vitro. Journal of Lipid Research, v.43, p.290-296, 2002. 
Rev. Bras. Saúde Prod. Anim., Salvador, v.16, n.3, p.591-605 jul./set.., 2015 http://www.rbspa.ufba.br ISSN 15199940

NATIONAL RESEARCH COUNCIL NRC. Nutrient requirements of dairy cattle. 7.ed. Washington: National Academy, 2001. 381p.

NETO, J.A.F.; REIS, R.B.; SAMPAIO, I.B.M.; SATURNINO, H.M.; SOUSA, B.M.; MOREIRA, E.M. Produção e composição do leite de vacas alimentadas com cana de açúcar suplementada com fontes de nitrogênio não protéico de diferentes degradabilidades ruminal. Ars veterinaria, v.29, n.1, p.52-59, 2013.

NUDDA, A.; BATTACONE, G.; BOAVENTURA NETO, O.; CANNAS, A.; FRACESCONI, A.H.D.; ATIZORI, A.S.; PULINA, G. Feeding strategies to design the fatty acid profile of sheep milk and cheese. Revista

Brasileira Zootecnia, v.43, n.8, p.445456, 2014.

OLIVEIRA, M.A.; REIS, R.B.; LADEIRA, M.M.; PEREIRA, I.G.; FRANCO, G.L.; SATURNINO, H.M.; COELHO, S.G.;ARTUNDUAGA, M.A.T.; FARIA, B.N.; SOUZA JÚNIOR, J.A. Produção e composição do leite de vacas alimentadas com dietas com diferentes proporções de forragem e teores de lipídeos. Arquivo Brasileiro de Medicina Veterinária e Zootecnia, v.59, p.759-766, 2007.

PEREIRA, E.S.; PIMENTEL, P.G.; BOMFIM, M.A.D.; CARNEIRO, M.S.S.; CÂNDIDO, M.J.D. Torta de girassol em rações de vacas em lactação: produção microbiana, produção, composição e perfil de ácidos graxos do leite. Acta Scientiarum: Animal Sciences, v.33, n.4, p.387-394, 2011.
PINA, D.S.; VALADARES FILHO, S.C.; VALADARES, R.F.D.; CAMPOS, J.M.S.; DETMANN, E.; MARCONDES, M. I.O.; TEIXEIRA, R.M.A. Consumo e digestibilidade aparente total dos nutrientes, produção e composição do leite de vacas alimentadas com dietas contendo diferentes fontes de proteína. Revista Brasileira de Zootecnia, v.35, n.4, p.1543-1551, 2006.

SARAN NETTO, A.; BARCELOS, B.; CONTI, R.M.C.; FERNANDES, R.H.R.; GREGHI, G.F., LIMA, Y.V.R. Substituição parcial de farelo de soja por uréia na alimentação de vacas girolandas em lactação. Journal Health Science Inst, v.29, n.2, p.139-142, 2011.

SARTORI, R.; GUARDIEIRO, M.M. Fatores nutricionais relacionados à reprodução da fêmea bovina. Revista Brasileira de Zootecnia, v.39, p.422432, 2010.

SKLAN, D.R.; ASHKENAZI, A.; BRAUN, A.; DEVORIN, A.; TEBORI, K. Fatty acids, calcium soaps of fatty acids, and cottonseeds fed to high yielding cows. Journal of Dairy Science, v.75, n.9, p.2463-2472, 1994.

SOUZA, V.M.; CALDEIRA, L.A.; ROCHA JÚNIOR, V.R.; ANTUNES, A.P. da S.; RUAS, J.R.M.; SANTANA, P.F.; COSTA, N.M.; BORGES, L.D.A. Efeito de níveis crescentes de ureia na alimentação de vacas sobre o rendimento, composição, perfil de ácidos graxos e sensorial do queijo minas frescal. Revista Brasileira de Ciência Veterinária, v.22, n.2, p.107113, 2015. 
Rev. Bras. Saúde Prod. Anim., Salvador, v.16, n.3, p.591-605 jul./set.., 2015 http://www.rbspa.ufba.br

SOFI, F.; BUCCIONI, A.; CESARI, F.; GORI, A.M.; MINIERI, S.; MANNINI, L.; CASINI, A.; GENSINI, G.F.;

ABBATE, R.; ANTONGIOVANNI, M.

Effects of a dairy product (pecorino cheese) naturally rich in cis-9, trans-11 conjugated linoleic acid on lipid, inflammatory and haemorheological variables: a dietary intervention study.

Nutrition, Metabolism and

Cardiovascular Diseases, v.20, p.117124, 2010.

VLAEMINCK, B.; FIEVEZ, V.;

TAMMINGA, S.; DEWHURST, R. J.;

VAN VUUREN, A.; DE

BRABANDER, D.; DEMEYER, D.

Milk odd- and branched-chain fatty

acids in relation to the rumen

fermentation pattern. Journal of Dairy

Science, v.89, p.3954-3964, 2006.

Data de recebimento: 16/01/2015

Data de aprovação: 11/09/2015 